\title{
A model of water-spray cooling effect on a continuous casting process
}

\author{
Hocine Mzad $^{1, *}$, Abdessalam Otmani ${ }^{1}$, Kamel Bey ${ }^{1}$, and Stanistaw Łopata ${ }^{2}$ \\ ${ }^{1}$ Department of Mechanical Engineering, Badji Mokhtar University of Annaba, P.O. Box 12, DZ-23000, Annaba, Algeria \\ ${ }^{2}$ Institute of Thermal Power Engineering, Cracow University of Technology, Poland
}

\begin{abstract}
The intention of this study is to give an idea about the influence of water-spray cooling on the solidification process of the liquid metal which enables to locate the shear region. The effect of spray heat transfer coefficient $\left(h_{\text {spray }}\right)$ during the liquid-to-solid transition through the cooled zone temperature and the metal latent heat of solidification are highlighted. A gray iron continuous casting process subjected to water-sprays cooling was simulated using the commercial code COMSOL MULTIPHYSICS 5.2. The obtained results show the great influence of $h_{\text {spray }}$ on the location of transition region as well as the relationship between $h_{\text {spray, }}$ wall outer temperature, latent heat dissipation, and the solidification time.
\end{abstract}

Keywords: Metal, Melting, Water-spray, Simulation, Heat transfer.

\section{Introduction}

The final metal structure is strongly affected by the set up cooling mode throughout liquid metal solidification. Continuous casting transforms molten metal into solid on a continuous basis and includes a variety of important commercial processes. These processes are the most efficient way to solidify large volumes of metal into simple shapes for subsequent processing.

Pascon et al. [1] developed a thermomechanical 2D model of the strand in the mould using the finite element code LAGAMINE. The approach uses the generalized plane strain state that allows a variable thickness of the slice in time, and provides one equation for the vertical force equilibrium.

Water is used to cool the mould in the initial stages of solidification, and then below the mould, where it is in direct contact with the newly solidified surface of the metal. A study by Tebbal and Mzad [2], that contributes to obtain a better quality of metal and steel with a possible minimum of energy and water expenses, lead to an empirical correlation defining the dispersion profile of a water jet beneath liquid sprayers.

Water cooling affects the product quality by controlling the heat removal rate that creates and cools the solid shell and generating thermal stresses and strains inside the solidified metal. The heat extraction coefficient during secondary cooling depends greatly on the surface temperature of the ingot, as represented by boiling water-cooling curves [3].
Several mathematical models are proposed for cooling a metal solidifying in a continuous casting mould, the purpose is to develop such a control to obtain the best possible steel quality, that is, minimizes the defects in the final product. More details about the history of the models are available in $[4,5]$.

The rate of heat transfer from a plate due to impinging of an array of water jets was investigated numerically through the solution of heat conduction equation, Mzad and Tebbal [6]. To highlight the parameters affecting spray cooling, the simulation was carried out for eight different sprayers in the range of ejected fluid pressure between 1 bar and 3 bars.

Aiming to reduce the occurrence of the surface and internal defects in the products, Ji and Yang [7] developed a dynamic secondary cooling control system. To accurately predict and control temperature in real time during the continuous casting process, a fast, accurate transient solidification and heat transfer model was developed, which provide feedback to a control system.

The disposition of nozzles that create overlapping jet zones results in dispersion profiles that depend on the experimental conditions. In order to understand the fluid behaviour in the overlap region, a research work [8] suggests a hydrodynamic investigation using a program of simulation based on the experimental correlations of pulverized water jets. The influence of the hydrodynamic parameters and the nozzle conception, by varying the

* Corresponding author: h_mzad@yahoo.fr 
water pressure, is highlighted which gives a very wide operating range.

In view of an increase of the casting speed under the constraint that the metallurgical length should be maintained constant, Bellet et al. [9] focuses on two points; the impact of local stress generated along the surface and subsurface of the cast product when passing by water spray sprinklers and the automatic determination of the water flow rate to be imposed to each sprinkler.

Recent developments in spray cooling applied to the second cooling are reviewed and evaluated by Raudensky et al. [10]. The quantification of heat transfer performance of spray cooling in continuous casting is then studied and the leading correlations developed for the heat transfer coefficient related to major spray cooling parameters are selected and compared.

A new Nusselt number correlation for spray cooling at large Reynolds numbers and high surface temperatures for water sprays impinging perpendicularly onto a flat plate is presented in Hnizdil's et al. research work [11]. A large set of experimental data on spray cooling of hot surfaces with water has been analysed, including the water temperature effects.

Mzad and Khelif [12] conducted a numerical investigation on heat transfer characteristics of water spray impingement cooling of stationary berylliumcopper alloy plate. The material is exposed to non-stop intensive cooling beneath a full cone spray nozzle. The only controlling parameter taken during the numerical study was water spray pressure in the working range of 1 to 4 bar.

In this paper, a numerical simulation of a continuous casting cooling process was performed based on a new model of temperature variation in the metal transition zone. Obviously, we will analyse the influence of the heat transfer coefficient $\left(h_{\text {spray }}\right)$ on some of thermal parameters affecting the solidification process like mould wall temperature and metal latent heat of solidification/fusion.

\section{Problem modelling}

A steady state continuous casting process is modelled and simulated using the commercial code COMSOL MULTIPHYSICS 5.2. The metal is first melted in a furnace and poured into a ladle. From the ladle the hot metal is transferred into the tundish. The hot metal is poured into the continuous casting machine from the tundish. The mould in the continuous casting process is water cooled; this helps speed up the solidification of the metal casting. The continuous casting does not completely harden in the mould; it does spend enough time in the water cooled mould to develop a protective solidified skin of an adequate thickness on the outside.

The thin shell like solidified metal withdraws from the mould and passes through a straightening roller. In the chamber the strand is water sprayed, which prevents porosity. After solidification, predetermined lengths of strands are cut into pieces using mechanical shears or travelling oxyacetylene torches (Fig. 1).

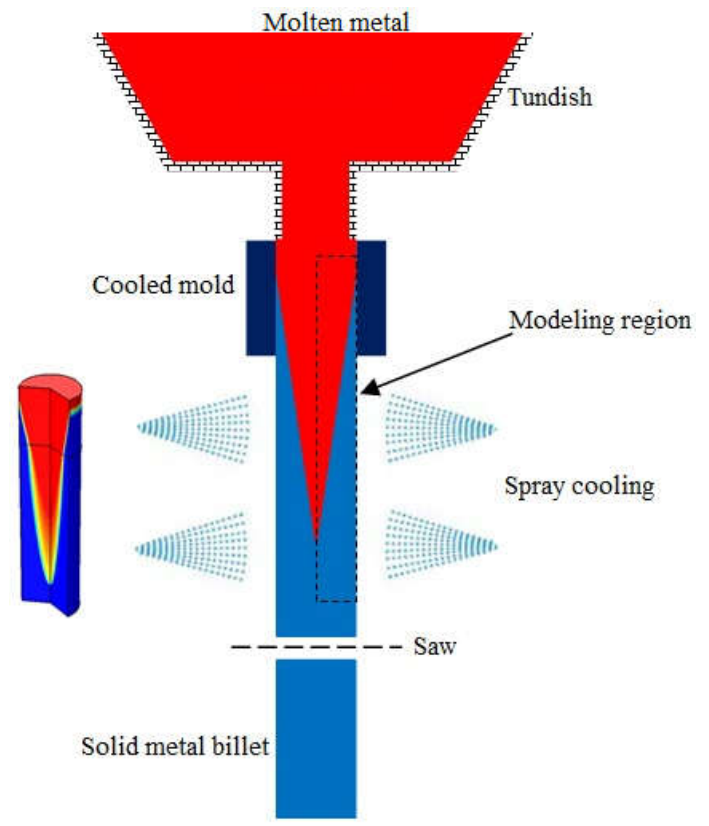

Fig. 1. Schematization of the studied case.

By assumption, in order to simplify the problem, the flow field of the liquid metal was not considered and it was assumed that there was no volume change during solidification. It has also been assumed that the casting speed, of $2.5 \mathrm{~mm} / \mathrm{s}$, is constant and uniform throughout the studied domain. In this work we have supposed an axisymmetric 2D geometry of the continuous casting domain composed of two rectangular sections. One represents the metal inside the mould and the second represents the spray cooled region outside the mould. In this region radiation cooling takes place. The considered material is a gray cast iron with the thermal properties shown in table 1 .

Table 1. Gray cast iron thermophysical properties.

\begin{tabular}{|c|c|}
\hline Parameter and designation & Value \\
\hline Latent heat of fusion $\left(\Delta H_{f}\right), \mathrm{J} / \mathrm{kg}$ & $240 \times 10^{3}$ \\
\hline Solidus temperature $T_{s}, \mathrm{~K}$ & 1356 \\
\hline Liquidus temperature $T_{l}, \mathrm{~K}$ & 1463 \\
\hline Specific heat $\left(C_{p_{-} s}\right)$ at $T_{s}, \mathrm{~J} /(\mathrm{kg} . \mathrm{K})$ & 660 \\
\hline Specific heat $\left(C_{p_{-}}\right)$at $T_{l}, \mathrm{~J} /(\mathrm{kg} . \mathrm{K})$ & 950 \\
\hline Thermal conductivity $\left(k_{s}\right)$ at $T_{s}, \mathrm{~W} /(\mathrm{m} . \mathrm{K})$ & 29 \\
\hline Thermal conductivity $(k l)$ at $T_{l}, \mathrm{~W} /(\mathrm{m} . \mathrm{K})$ & 26 \\
\hline Density $\left(\rho_{s}\right)$ at $T_{s}, \mathrm{~kg} / \mathrm{m}^{3}$ & 6964 \\
\hline Density $\left(\rho_{l}\right)$ at $T_{l}, \mathrm{~kg} / \mathrm{m}^{3}$ & 6368 \\
\hline Estimated viscosity $\left(\mu_{l}\right)$ at $T_{l}, \mathrm{~Pa} . \mathrm{s}$ & 0.0143 \\
\hline
\end{tabular}

The heat conduction equation which describes the heat transfer of the studied case is written as follows:

$$
\rho C_{p} \frac{\partial T}{\partial t}+\rho C_{p} u \nabla T+\nabla q=Q
$$


Hypothetically, $C_{p_{-} s}$ is supposed constant in solid phase, but in liquid phase $C_{p_{-}}$is evaluated using the following formula:

$$
C_{p_{-} l}=C_{p_{-} s}+\frac{\Delta H}{T_{m}}
$$

The steady state heat equation of continuous casting process is merely written:

$$
\rho C_{p} u \Delta T+\Delta(-k \Delta T)=0
$$

The density and the specific enthalpy are respectively:

$$
\begin{gathered}
\rho=\theta p_{s}+(1-\theta) \rho_{l} \\
H=\frac{1}{\rho}\left[\theta \rho_{s} H_{s}+(1-\theta) \rho_{l} H_{l}\right]
\end{gathered}
$$

During the liquid to solid transformation, a significant amount of latent heat is released and the total amount of heat released per unit mass during the transition is given by the enthalpy variation $\Delta H$.

Obviously, the specific heat varies before, during and after the transition:

$$
\Delta C_{p}=\frac{\Delta H}{T}
$$

After some formal transformations:

$$
C_{p}=\frac{1}{\rho}\left(\theta_{1} \rho_{S} C_{p_{-} s}+\theta_{2} \rho_{l} C_{p_{-} l}\right)+\Delta H_{f} \frac{\partial \alpha_{m}}{\partial T}
$$

where:

$$
\alpha_{m}=\frac{(1-\theta) \rho_{l}-\theta \rho_{s}}{2\left[\theta \rho_{S}+(1-\theta) \rho_{l}\right]}
$$

The thermal conductivity varies allowing the expression:

$$
k=\theta k_{s}+(1-\theta) k_{l}
$$

The convection heat flux transferred to the mould by the liquid metal can be estimated using Newton equation:

$$
q_{0}=h\left(T_{e x t}-T\right)
$$

where, $h=800 \mathrm{~W} /\left(\mathrm{m}^{2} . \mathrm{K}\right)$.

Similarly, convection at the outer cooled zone is computed using the equation 10. $T_{\text {ext }}$ and $T$ are respectively external and mould wall temperatures. In this situation, $h$ became spray heat transfer coefficient.

As mentioned before, radiation occurs during the continuous casting process, and it is described by StefanBoltzmann equation in which the temperature $T$ is expressed in Kelvin:

$$
q_{0}=\varepsilon \sigma\left(T_{\text {ext }}{ }^{4}-T^{4}\right)
$$

where $\sigma$ symbolise the Stefan-Boltzmann constant and $\varepsilon$ the material emissivity $(\varepsilon=0.8)$.

\section{Results and discussion}

The study consists of water-spray cooling simulation. Figure 2 illustrates the result of this mode of cooling. One can distinguish a complete solidification of the liquid metal before reaching the cutting zone, which is sought in continuous casting processes.

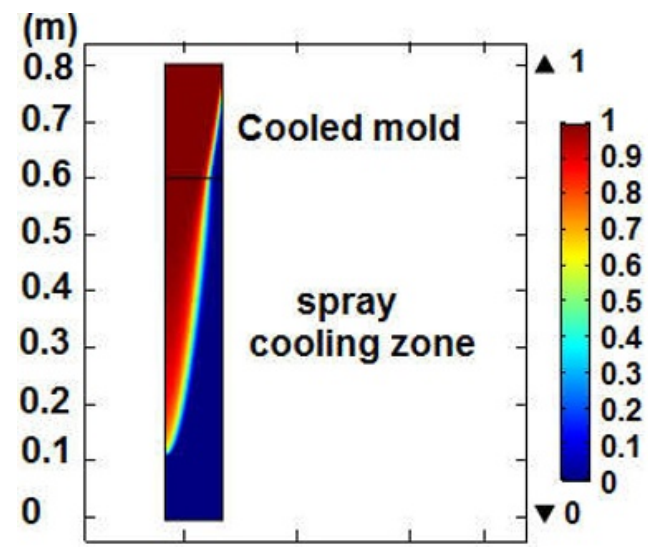

Fig. 2. Spray cooling effect on metal solidification.

The spray cooling process is very efficient since it accelerates the process through a large amount of heat evacuation without water wasting, which imply time and energy saving.

In this section we draw attention to the influence of heat transfer coefficient ( $\left.h_{\text {spray }}\right)$ on the cooling rate of the metal. Even if the values adopted during the simulation are below the actual values [6], the obtained results show very significantly the effectiveness of water spray cooling (Fig. 3). Indeed, the increase in $h_{\text {spray }}$ accelerates heat transfer.

If we consider the level $L=0.3 \mathrm{~m}$, the wall temperature drops to $35 \%$ corresponding to $h_{\text {spray value of }}$ $1500 \mathrm{~W} /\left(\mathrm{m}^{2} . \mathrm{K}\right)$. If $h_{\text {spray }}$ value is higher, of the order of $6000 \mathrm{~W} /\left(\mathrm{m}^{2} . \mathrm{K}\right)$, the decrease in wall temperature is almost $70 \%$.

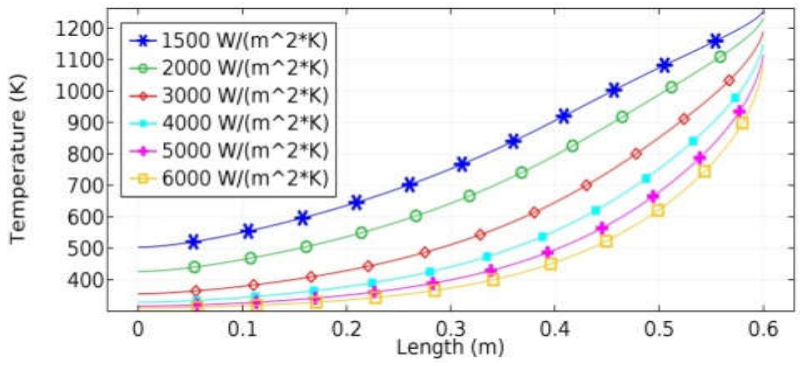

Fig. 3. Influence of spray heat transfer coefficient on wall temperature.

The computed values of latent heat of solidifying are obtained showing different sites of heat evacuation depending on the initial value of $h_{\text {spray }}$ (Fig. 4). Visibly, the dissipation of the latent heat is slower when $h_{\text {spray }}$ decreases, since the wall temperature remains relatively high. 


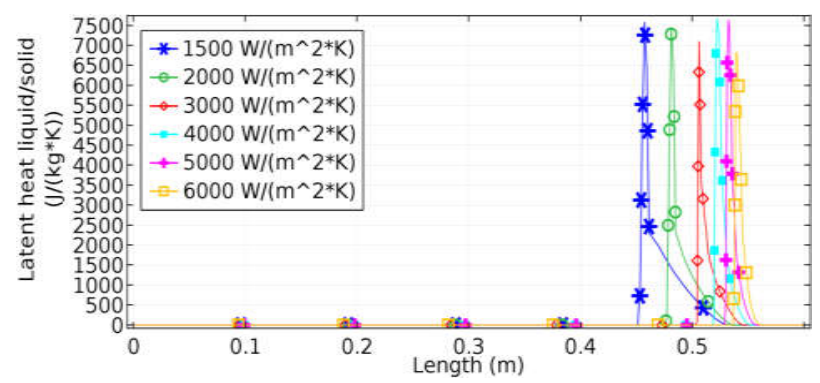

Fig. 4. Influence of spray heat transfer coefficient on latent heat.

The solidification is faster for higher heat transfer coefficients, e.g for $h_{\text {spray }}=6000 \mathrm{~W} /\left(\mathrm{m}^{2} . \mathrm{K}\right)$ metal solidification begins at $L=0.5615 \mathrm{~m}$ and finish at $L=0.537 \mathrm{~m}$, whereas, for $h_{\text {spray }}=1500 \mathrm{~W} /\left(\mathrm{m}^{2} . \mathrm{K}\right)$ the process begins at the level $L=0.532 \mathrm{~m}$ and finish at $L=0.451 \mathrm{~m}$ (Fig. 5). This investigation is an attempt to take account of the evolution of latent heat and to determine its effect on the rate of solidification which implicitly has a remarkable influence on the location of the transition region (Fig. 6). The metal solidifies gradually from the outer walls, and the rate of advance of crystallization is thought to play an important part in the segregation of impurities from the liquid metal.

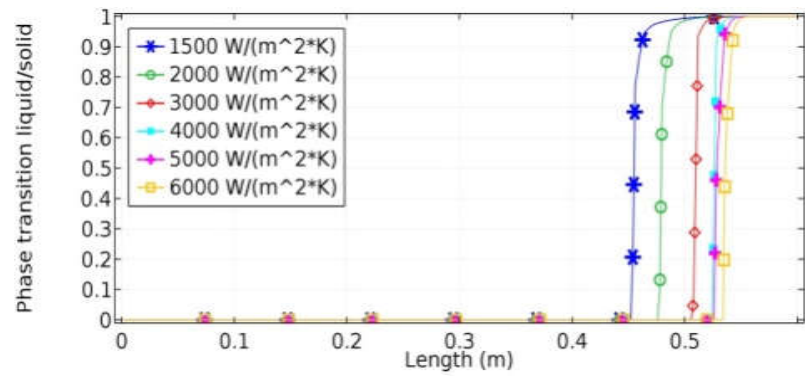

Fig. 5. Influence of spray heat transfer coefficient on phase transition.

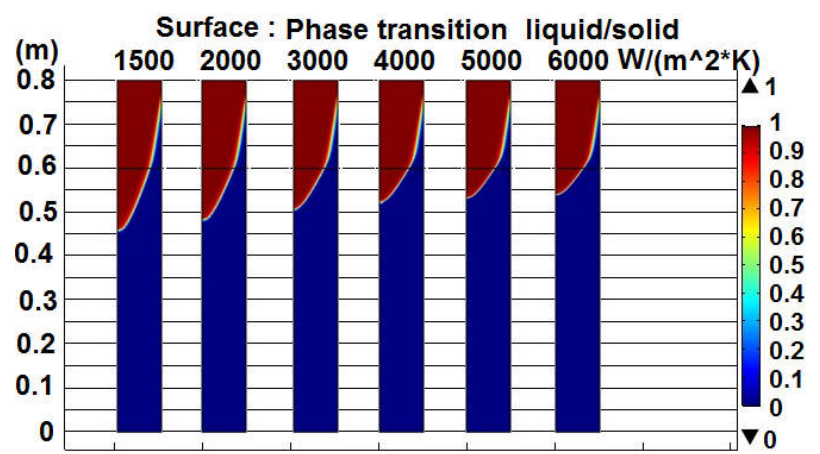

Fig. 6. Influence of spray heat transfer coefficient on transition localization.

\section{Final conclusions}

The use of water spray cooling through horizontal nozzles in continuous casting process allows a uniform and homogeneous solidification of the metal which ensures a cutting zone entirely solid.
The localization of the liquid-to-solid transition zone is strongly affected by spray heat transfer coefficient. Difference between latent heats of melting and solidifying for the considered metal is probably due to different heat capacities for undercooled melt and solid state.

It is assumed that the performed simulations will be possible to use in optimization of real casting process, but it would be very useful also, due to an insufficient experimental and theoretical data in the accessible literature in case of phase transitions, to perform more significant experiments.

\section{References}

1. F. Pascon, A.M. Habraken, M. Bourdouxhe, F. Labory, Mechanics and Industry 1, 61-70, in French (2000)

2. M. Tebbal, H. Mzad, Forsch. im Ingenieurwesen, 68, 126-132 (2004)

3. J. Sengupta, B.G. Thomas, M.A. Wells, Metallurgical and Materials Transactions A, 36, 187-204 (2005)

4. A.V. Lotov, G.K. Kamenev, V.E. Berezkin, K. Miettinen, Applied Mathematical Modelling 29, 653-672 (2005)

5. S.V. Lukin, N.I. Shestakov, T.I. Strashko, A.V. Zverev, Russian Metallurgy 3, 184-188 (2007)

6. H. Mzad, M. Tebbal, Heat Mass Transfer 45, 287 295 (2009)

7. Z. Ji, J. Yang, 3rd Int. Conf. on Intelligent Networks and Intelligent Systems (ICINIS), (Shenyang, China, 2010)

8. H. Mzad, M. Elguerri, Atomization and Sprays 22, 447-460 (2012)

9. M. Bellet, L. Salazar-Betancourt, O. Jaouen, F. Costes, 8th European Continuous Casting Conference (Graz, Austria, 2014)

10. M. Raudensky, A.A. Tseng, J. Horsky, J. Kominek, Metallurgical Research and Technology 113, 509 (2016)

11. M. Hnizdil, M. Chabicovsky, M. Raudensky, T.W. Lee, J. of Flow Control Measurement and Visualization 4, 104-113 (2016)

12. H. Mzad, R. Khelif, Procedia Engineering 157, 106-113 (2016) 